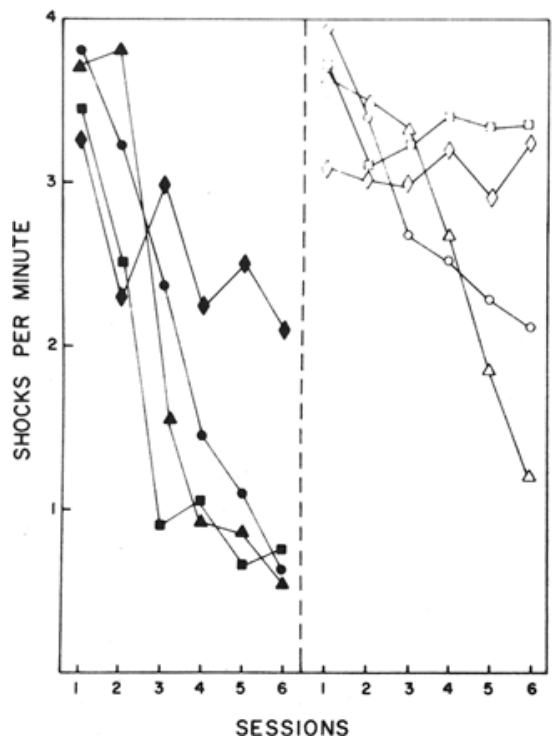

Fig. 2. Shock frequency per session for each S. Left panel is for response contingent stimulus Ss; right panel is for Ss not receiving the stimulus.

significant $(U=1, p=.057)$ when the one obvious deviate (closed diamond) was excluded. This $S$ was given seven additional sessions with little change in performance. Response rate does appear to have been facilitated by the stimulus, but this conclusion is tenuous.

The consequence of responding in a free-operant situation is a reduction in shock frequency. Figure 2 shows the average number of shocks per minute for each S. Analysis of variance did show a significant difference $(F=13.62, \mathrm{df}=1 / 6$, $\mathrm{p}<.05)$ between conditions. Reduction in shock frequency for the response-contingent stimulus $S s$ is particularly obvious for three of the Ss. The discrepancy between response rate and shock frequency is due to an imperfect inverse relation between the two measures.

\section{DISCUSSION}

It is clear that a response-contingent stimulus in free-operant avoidance has a decided influence on the acquisition of free-operant avoidance. However, theoretical interpretation of the results of this study is equivocal. In positive reinforced behavior, pairing a neutral stimulus with a response and reinforcer is the paradigm for establishing the neutral stimulus as a secondary reinforcer. With the exception of a clearly defined primary reinforcer, the procedures of this study are analogous to procedures for producing secondary reinforcement. The reinforcing event associated with a response in free-operant avoidance is not apparent, but Anger's (1963) conditioned aversive temporal-stimuli hypothesis does propose a plausible reinforcer. Reinforcement stems from a reduction in aversiveness following a response, and aversiveness again increases to a peak immediately prior to the next scheduled shock. Consequently, pairing a neutral stimulus with a reduction in aversiveness might be expected to establish the neutral stimulus as a secondary reinforcer. According to Kimble (1961), stimuli associated with the termination of "pain" may acquire positive reinforcing properties. This idea has not been systematically investigated, but the acceleration in response rate for $S s$ in response-contingent stimulus group may be partially explained by this formulation. The Anger hypothesis, on the other hand, would predict a lower response rate that would more closely match the requirement dictated by the length of the R-S interval. However, clear temporal discrimination may appear only after much extended training. The results of this exploratory study do show that a response-contingent stimulus influences the course of acquisition in free-operant avoidance. Since the response-contingent stimulus was superimposed on the normal course of acquisition, it is difficult to ascertain the function of the stimulus. Thus the exact nature and extent of stimuli correlated with responses in free-operant avoidance must await further investigation.

\section{REFERENCES}

ANGER, D. The role of temporal discrimination in the reinforcement of Sidman avoidance behavior. Journal of the Experimental Analy sis of Behavior, 1963, 6, 477-506.

BOLLES, R. C., \& POPP, R. J., JR. Parameters affecting the acquisition of Sidman avoidance. Joumal of the Experimental Analysis of Behavior, 1964, 7, 315-321.

BOLLES, R. C., \& GROSSEN, N. E. Effects of an informational stimulus on the acquisition of avoidance behavior in rats. Journal of Comparative \& Physiological Psychology, $1969,68,90-99$.

KIMBLE, G. A. Hilgard and Marquis' Conditioning and learning. New York: Appleton-Century-Crofts, 1961.

SIDMAN, M. Avoidance conditioning with brief shock and no exteroceptive warning signal. Science, 1953, 118, 157-158.

SIDMAN, M. Reduction of shock frequency as reinforcement for avoidance behavior. Journal of the Experimental Analysis of Behavior, $1962,5,247-257$

\title{
Retention of avoidance running ${ }^{1}$
}

ROBERT S. BEECROFT, University of North Dakota, Grand Forks, N. Dak. 58201 , and BONNIE G. FISHER, University of Iowa, Iowa City, Iowa 52240

Resistance to extinction of avoidance running was studied at four retention intervals. Resistance to extinction decreased from $1 \mathrm{~min}$ to $4 \mathrm{~h}$, held steady at $24 \mathrm{~h}$, then decreased again to $144 \mathrm{~h}$. Running times increased for the delayed-retention $S s$

In this experiment a rat is trained to run from the startbox through a 6 -ft alley to the goalbox in less than $3 \mathrm{sec}$, thereby avoiding the shock that accompanies slower runs. After this single avoidance run, simple extinction without shock begins on the next trial after retention intervals varying from $1 \mathrm{~min}$ to $144 \mathrm{~h}$. Thus, this is a retention study using a resistance to extinction criterion. The limited amount of acquisition training should be noted. However, our previous studies indicate that training Ss to the criterion of three successive avoidances (Beecroft, 1967) or giving 10 training trials beyond the first avoidance (Beecroft, Fisher, \& Bouska, 1967, Experiment 1) does not materially increase resistance to extinction. Also, we were interested in determining if the Kamin effect (Kamin, 1957) would appear in extinction data; there is some evidence that the Kamin effect is most conspicuous when initial avoidance training is limited (Anderson, Johnson, Schwendiman, \& Dunford, 1966).

\section{METHOD}

The runway consisted of a duplex startbox, a 6-ft alley, and a large black goalbox (cf. Brown, Martin, \& Morrow, 1964, for details). All rats were trained to 
one avoidance with a nominal $3-\mathrm{sec}$ avoidance interval (electronically timed records indicated the avoidance interval was closer to $2.9 \mathrm{sec}$ ). On the following trial, whenever that began, shock was discontinued and extinction testing conducted until $S$ failed to enter the goalbox within $60 \mathrm{sec}$ or completed running 30 extinction trials. Four retention intervals ( $1 \mathrm{~min}, 4 \mathrm{~h}, 24 \mathrm{~h}$, and $144 \mathrm{~h}$ ) intervened between the avoidance criterion trial and the first extinction trial. The Ss were returned to their home cages in all but the 1-min condition. Training shock intensity was $55 . \mathrm{V}$ ac through $10 \mathrm{~K}$ resistance, goalbox detention was $30 \mathrm{sec}$, the intertrial interval was $60 \mathrm{sec}$, and there was no warning signal. The Ss were 40 female hooded rats, 98-105 days old when trained. Six Ss that did not learn within 30 trials were discarded.

\section{RESULTS}

The rats in this experiment were from different breeding stock than in our other studies and they were somewhat slower in avoidance learning. Their mean trial of first avoidance was 12.3 compared to a mean of 8.9 for the 52 simple-extinction Ss in three previous experiments (Beecroft, Bouska, \& Fisher, 1967, Experiment 1; Beecroft \& Fisher, 1969; Beecroft, Fisher, \& Bouska, 1967, Experiment 3). This difference is reliable $(t=2.70, \quad d f=90, \quad p<.01)$. Despite the difference in speed of acquisition, resistance to extinction is about the same. The $10 \mathrm{Ss}$ in the present experiment who were extinguished with only the intertrial interval of $1 \mathrm{~min}$ between acquisition and extinction averaged 16.9 completed runs; the $52 \mathrm{Ss}$ from previous studies who were similarly treated averaged 15.1 completed trials. This difference is not significant. The lack of an extinction differential, despite the difference in amount of acquisition training, is not surprising in light of the findings mentioned in the introduction to this paper. Also, it is interesting to observe that for the 52 previous Ss, the Pearson $r$ between first avoidance trial and extinction trials completed was zero and for the 10 comparable $\mathrm{Ss}$ in the present experiment was an insignificant .34. These correlations show that resistance to extinction is unaffected by the variation in the number of trials necessary to bring individual rats to the avoidance criterion. In sum, then, there is no reason to believe that the somewhat slower avoidance learning of the Ss in the present experiment biased the extinction data in any way.

As noted, the 1-min Ss averaged 16.9 completed extinction trials. Three $\mathrm{Ss}$ in this group ran the maximum 30 trials; they were the only rats in the study to do so. Resistance to extinction was less in the other groups. Mean trials completed were $7.3,8.3$, and 2.4 for the 4-, 24-, and 144-h groups, respectively. A simple analysis of variance gave a significant $F$ of 7.32 $(\mathrm{df}=3,36, \mathrm{p}<.01)$. The slight difference between the 4- and 24-h groups is associated with the fact that four 4 -h Ss extinguished on the first trial whereas only one of the 24-h Ss did. The top five runners in each group ran the same total number of trials. Four of the 144-h Ss extinguished on the 1st trial and one each quit on the 2 nd, 3rd, 4th, 5th, 7th, and 9th trials.

An analysis of running times on the first extinction trial is of interest. For the $1-\mathrm{min}$ Ss, running times ranged from 1.9 to $3.7 \mathrm{sec}$, with a median of 3.1. For delayed-retention $S$ s who did not extinguish on the first trial, running times ranged from 3.1 to $39.2 \mathrm{sec}$, with a median of $8.3 \mathrm{sec}$. Every running time was slower than the median for 1-min Ss and only two times were less than the slowest running time of $3.7 \mathrm{sec}$ registered by a $1-\mathrm{min} \mathrm{S}$. Thus, there was a loss of response speed on the order of $5 \mathrm{sec}$ for the typical rat whose extinction was postponed. A further analysis of running times was made for the 15 delayed-retention Ss who ran at least five extinction trials. Median running time decreased from $8.2 \mathrm{sec}$ on the first extinction trial to $5.0 \mathrm{sec}$ on the second trial and $4.8 \mathrm{sec}$ on the third trial, followed by a gradual increase on succeeding trials. In contrast, the median running time of the 1 -min Ss held near $3 \mathrm{sec}$ for six trials before starting to rise.

\section{DISCUSSION}

What effect does a retention interval have on avoidance running? First, about a third of the animals fail to enter the goalbox within $60 \mathrm{sec}$, i.e., extinction occurs within the first trial. Second, the Ss that do make it to the goalbox run slowly. Third, for Ss that do not extinguish within a few trials, speed recovers and then slackens in slower runs that presage extinction. Fourth, the retention function seems to be bisegmental. The first decrement in avoidance running in our data is between $1 \mathrm{~min}$ and $4 \mathrm{~h}$, then, after no change from 4 to $24 \mathrm{~h}$, a second decrement occurs between 24 and $144 \mathrm{~h}$. The first decrement occurs within minutes of the last training trial and is well authenticated. Its temporal course has been most carefully charted by Melvin, Martin, \& Parsons (1965). They found a decrement in escape running with a 6 -min retention interval compared to a 1-min control. An even larger decrement was observed at $18 \mathrm{~min}$, although there was little further change at 54 and $162 \mathrm{~min}$. The second decrement is apparent in an avoidance study by Moyer (1958), in which resistance to extinction was greater at $1 \mathrm{~h}$ than at various intervals from 2 to 32 days.

Kamin (1957, 1963) obtained a U-shaped function relating avoidance responding following resumption of avoidance training to the length of the interval between training and retraining. In the Kamin effect, the bottom of the $U$ is found from 1 to $6 \mathrm{~h}$ following the original training, with performance after $24 \mathrm{~h}$ more or less at parity with performance after the shortest retention intervals (e.g., 1.5 $\mathrm{min}$ ). Although the slight inversion from 4 to $24 \mathrm{~h}$ obtained in the present experiment is consistent with the Kamin effect, there was no $U$ shape since resistance to extinction at $24 \mathrm{~h}$ was down so much relative to $1 \mathrm{~min}$. This suggests that the Kamin effect is not a simple retention phenomenon, but rather one that involves the continued use of the avoidance contingency and/or aversive stimulation after the retention interval. It should be pointed out that we really do not know if the Kamin effect does occur in the runway avoidance situation even if avoidance training is continued after the retention interval.

\section{REFERENCES}

ANDER SON, D. C., JOHNSON, L. SCHWENDIMAN, G., \& DUNFORD, G. Retention of an incompletely learned avoidance response: Some problems with replication. Psychonomic Science, 1966, 6, 23-24.

BEECROFT, R. S. Near-goal punishment of avoidance running. Psychonomic Science, $1967,8,109-110$.

BEECROFT, R. S., BOUSKA, S. A., \& FISHER, B. G. Punishment intensity and self-punitive behavior. Psychonomic Science, 1967, 8, 351-352.

BEECROFT, R. S., \& FISHER, B. G. Avoidable punishment and self-punitive behavior. Psychonomic Science, 1969, 15, 243-244.

BEECROFT, R. S., FISHER, B. G., \& BOUSKA, S. A. Punishment continuity and self-punitive behavior. Psychonomic Science, 1967, 9, 127-128.

BROWN, J. S., MARTIN, R. C., \& MORROW, M. W. Self-punitive behavior in the rat: Facilitative effects of punishment on resistance to extinction. Journal of Comparative \& Physiological Psychology, 1964, 57, 127-133. KAMIN, L. J. The retention of an incompletely learned avoidance response. Journal of Comparative \& Physiological Psychology, $1957,50,457-460$.

KAMIN, L. J. Retention of an incompletely learned avoidance response: Some further analyses. Journal of Comparative \& Physiological Psychology, 1963, 56, 713-718. MELVIN, K. B., MARTIN, R. C., \& PARSONS, G. Delayed extinction of escape responses: A parametric study. Psychonomic Science, 1965 , 2, 247-248.

MOYER, K. E. Effect of delay between training and extinction on the extinction of an avoidance response. Journal of Comparative \& Physiological Psychology, 1958, 51, 116-118. NOTE

1. This research was supported by PHS Grant 5 R01-MH 11734-04 to Judson S. Brown. We wish to thank Professor Brown for his comments on the manuscript. 